\title{
O uso das tecnologias de informação e comunicação no ensino de Química e os aspectos semióticos envolvidos na interpretação de informações acessadas via web
}

\section{The use of information and communication technologies in Chemistry teaching and the semiotics aspects involved in the information interpretation through web access}

\author{
Vitor de Almeida Silva ${ }^{1}$ \\ https://orcid.org/0000-0002-8943-8927 \\ Márlon Herbert Flora Barbosa Soares ${ }^{1}$ \\ https://orcid.org/0000-0002-3273-8603
}

\begin{abstract}
Resumo: O uso das tecnologias de informação e comunicação (TIC) evidencia uma transformação nos processos de ensino e de aprendizagem, destacando a informação como relevante para uso das TIC em sala de aula. Este artigo, recorte de uma pesquisa de doutorado, discute o acesso às informações e o uso das TIC no ensino de química e os aspectos semióticos envolvidos na interpretação de informações para a verificação da aprendizagem. A pesquisa foi realizada em uma escola pública e investigou como os estudantes interpretam e manipulam as informações acessadas via web. Pesquisou, também, como fazem a correlação abstrata entre signos para elaboração de um raciocínio representativo de objetos ausentes. Constatou-se que a informação acessada de forma autônoma e manipulada pelos alunos se configura como incipiente para o desenvolvimento da aprendizagem, sendo fundamental a figura mediadora do professor para um uso significativo em sala de aula da informação acessada pela internet.
\end{abstract}

Palavras-chave: Ensino de química. Informação. Aprendizagem. Tecnologias de informação e comunicação. Semiótica.

\begin{abstract}
The use of information and communication technologies (ICT) results in a transformation in the teaching-learning process, highlighting the relevance of the information for the use of ICT in the classroom. This paper, part of a doctorate degree research, discusses the information access and the use of ICT in chemistry teaching and the semiotic aspects involved in the interpretation of information to verify the learning process. The research took place in a public school and investigated how the students interpreted and manipulated information obtained through the web. It also investigated how the pupils made the abstract correlation among semiotics signs in order to formulate representative reasoning about absent objects. It was verified that the information accessed in an autonomous way and manipulated by the students was insufficient to learning development, showing that teacher mediation is fundamental for the use of ICT with the purpose of making significant use of information through internet access.
\end{abstract}

Keywords: Chemistry teaching. Information. Learning. Information and communication technologies. Semiotics.

\footnotetext{
${ }^{1}$ Universidade Federal de Goiás (UFG), Goiânia, GO, Brasil. E-mail: < vitor.almeida@ufg.br>.
} 


\section{Introdução}

Conduzir o desenvolvimento da aprendizagem a partir do uso de tecnologias não é uma tarefa trivial. É necessário abordar o termo tecnologia, visualizando-o como um conjunto de artefatos e dispositivos que incorporam uma amplitude de práticas que se desenvolvem e se organizam de acordo com lógicas sociais e organizacionais específicas; e que delimitam uma compreensão dos avanços técnico-científicos que interagem, influenciam e são influenciados pelos aspectos políticos, sociais, econômicos e filosóficos em que se encontram inseridos.

Essa característica integradora entre tecnologia e sociedade fomenta a hibridação entre os meios de comunicação e os avanços tecnológicos amparando a estrutura social e orgânica dos sujeitos que vivem em comunidade. Esse movimento de convergência de tecnologias, principalmente do campo da computação e das representações dos meios midiáticos, é definido por Damásio (2007) como Tecnologias de Informação e Comunicação, as TIC. Devemos considerar, e Damásio (2007) faz essa ponderação, que essa convergência corresponde ao poder de processamento e manipulação computacional, em uma linguagem específica, de qualquer representação comunicacional, assim como sua transmissão para alguma plataforma que seja capaz de ler, interpretar e retransmitir esta linguagem.

A inserção tecnológica na esfera social se configura como um fator essencial para a difusão, familiarização e utilização das TIC nos diferentes campos sociais. O poder de penetrabilidade das TIC e sua extensa utilização promovem a propagação de concepções ingênuas a respeito de seu papel na educação. Tais concepções apontam o uso das TIC com o objetivo de aprimorar a aprendizagem dos indivíduos e assim melhorar os processos de ensino e de aprendizagem.

Contudo, faz-se necessário compreender que a forma como se desenvolvem os indivíduos diante dos campos tecnológico e educacional são completamente diferentes. A capacidade de aprender não está centrada na habilidade de manipulação dos aparatos tecnológicos. A esse respeito Papert (1994, p. 5) afirma que a aprendizagem corresponde à "capacidade de aprender novas habilidades, de assimilar novos conceitos, de avaliar novas situações, lidar com o inesperado".

Considerando tais apontamentos podemos elencar os seguintes questionamentos concernentes à utilização das TIC em sala de aula e ao desenvolvimento da aprendizagem: qual a conduta comportamental dos sujeitos diante da informação pesquisada por meio das TIC? Como a relação dialógica entre estrutura cognitiva e signos semióticos fomenta o desenvolvimento da aprendizagem?

Para responder aos questionamentos propostos, devemos associar o uso das TIC nos processos de ensino e de aprendizagem a partir de uma característica inovadora. Isso significa instigar o sujeito a visualizar, compreender e manipular a informação para elaboração de um pensamento crítico. 


\section{Fundamentação teórica}

\section{A informação como um bem de consumo}

Assumir o uso das TIC em sala de aula como proposta inovadora de ensino significa fundamentarmos o desenvolvimento da aprendizagem a partir de uma dinâmica autônoma de acesso, interpretação e manipulação da informação. O conceito de informação, neste contexto, se amplia para além de sua concepção etimológica, incorporando em seu sentido uma dimensão ontológica e epistemológica.

Capurro (2014) considera que a informação assume um sentido ontológico centrado na ação de dar forma a algo material, inferindo também uma perspectiva epistemológica, pois se configura como ato de comunicar conbecimento a uma pessoa. Tanto o sentido ontológico quanto o epistemológico estão intimamente ligados.

Ampliar o conceito de informação para além de sua estrutura etimológica significa esboçar uma compreensão do conteúdo informacional, o que implica em um desdobramento cognitivo do sujeito, direcionando-o ao desenvolvimento de um comportamento que seja capaz de reconhecer e representar os signos distintos presentes em uma informação e interpretá-los de forma complementar.

No entanto, suplantar as bases etimológicas e epistemológicas que envolvem o conceito de informação significa condicionar a concepção do termo a um status quantitativo, subordinado à codificação binária. É o que acontece com o surgimento da digitalização dos processos informacionais, após o advento e a aplicação dos computadores aos processos bibliográficos. Vários autores destacam esse processo como o início da Ciência da Informação e sua sucessiva progressão social para o estabelecimento do que ficou conhecido como sociedade da informação (CAPURRO, 2014; CAPURRO; HJORLAN, 2007; CASTELLS, 2013; EPSTEIN, 1988).

Elaborada a partir dos fundamentos das ciências exatas, da engenharia e da computação, a Ciência da Informação confere à informação o sentido de transmissora de determinada mensagem. Moles (1978, p. 24) destaca que a informação corresponde a um "grupo finito e ordenado de elementos de recepção tirados de um 'repertório' e reunidos numa estrutura". Shannon (1948) é mais radical em sua concepção, vinculando a informação à formatação de mensagens que um emissor comunica a um receptor. A teoria matemática da comunicação de Shannon (1948) resume a definição de informação à possibilidade de seleção de mensagens e, como afirma Capurro (2014), está intimamente ligada a uma seleção precisa de signos capazes de serem codificados e decodificados.

Diante dessa perspectiva, o conceito de informação assume uma característica técnica na sociedade da informação, sendo tratada como um produto altamente manipulável. A noção de dar forma a algo ou comunicar conbecimento a alguém é literalmente substituída pela transmissão de uma mensagem capaz de ser traduzida em possiveis signos a serem codificados, como interpreta Capurro (2014).

A noção de informação dialogada com a concepção técnica substitui o caráter subjetivamente humano por uma estruturação algorítmica baseada na manipulação técnico-matemática de um maquinário capaz de traduzir e de codificar mensagens. O que apresentava uma característica substancial, amparada pela forma e ideia, se resume a processos de transmissão e recepção de mensagem. 
Capurro (2014) considera que ao admitirmos a correlação entre o número de seleções possíveis de uma informação, a fim de criar uma mensagem, e a probabilidade de escolher, esta seleção apresenta uma abertura para atribuirmos uma característica formal ou objetiva da informação, nos distanciando dos aspectos semânticos e pragmáticos que são característicos aos sistemas psíquicos e sociais que envolvem o uso moderno do conceito de informação.

A informação nessa perspectiva se destaca como um bem público de consumo, definida por Kollock (1999) como qualquer coisa que é produzida por alguém e que está disponível para que todos possam se beneficiar de seu uso. O autor enfatiza que esses bens públicos se destacam por duas características fundamentais: (1) é indivisível, pois seu consumo por uma pessoa não limita a sua disponibilidade para outros sujeitos; (2) é não excludente, uma vez que qualquer indivíduo poderá fazer uso dele, independentemente de ter ou não contribuído para sua produção ou existência.

O conteúdo informacional, acessível por qualquer sujeito em distintas mídias, se enquadra na característica de bem público, uma vez que apresenta as características fundamentais apresentadas por Kollock (1999). Utilizar as informações acessadas pelas TIC como um mecanismo de inovação aos processos de ensino e de aprendizagem significa compreendermos a informação como um bem público capaz de fundamentar o pensamento semiótico que envolve a interpretação do conteúdo midiático.

Nesse sentido, promover a aprendizagem a partir do acesso e utilização das informações significa habilitar o indivíduo a compreender o status ontológico e epistemológico da informação, assumindo uma autonomia e responsabilidade de provedor de um conteúdo informacional relevante, ou, especificamente, um produtor de bens públicos de consumo.

Para que isso ocorra, Kollock (1999) sugere que há a necessidade de superar dois desafios. O primeiro se refere à motivação: contribuir individualmente para a produção de um bem público, apesar da tentação de não se fazer nada. O segundo desafio é a coordenação: mesmo em um grupo de indivíduos motivados e empenhados em desenvolver um bem público, seus membros deverão coordenar seus esforços, o que irá envolver um conjunto de dificuldades e custos.

A inserção das TIC em sala de aula se estabelece como uma interface que engloba os desafios apresentados por Kollock (1999), já que apontar as TIC como um processo inovador da aprendizagem corresponde a visualizar a informação como um conjunto de signos capazes de impressionar a estrutura cognitiva do sujeito. Ademais, a informação os direciona a uma construção de significados que contemple uma perspectiva crítica e autônoma na produção de novos bens públicos.

Como processo inovador, o uso das TIC assume que todo ambiente midiático se encontra imerso em uma ambivalência econômica de oferta de bens públicos e venda publicitária. É o que Spyer (2007, p. 30) denomina como Economia de Doação ou de Oferta, conceituando-a como uma "transferência obrigatória de objetos ou serviços inalienáveis entre negociantes com vínculos e obrigações entre si”. Spyer (2007) ainda afirma que a Economia de Doação associada aos grupos, principalmente em ambientes virtuais, é regida pelo esforço de uma pessoa em sanar as dúvidas ou inquietações de um grupo, e que no futuro algum outro participante irá ajudá-lo com o surgimento de outra dificuldade. Porém, a política da Economia de Doação não pressupõe uma obrigatoriedade da retribuição ou transação recíproca de doações. Esta característica faz com que o usuário dos ambientes virtuais não se preocupe com o significado e relevância 
da informação e não se sinta motivado a produzir ou contribuír com os bens públicos, o que virtualmente se configura como informação. Spyer (2007) considera isso um problema na política de troca entre grupos, o que favorece os indivíduos a se colocarem na posição de receptores passivos, se beneficiando do esforço e da ação de outros.

Ampliar a visão de informação para além de um bem público significa resgatar, no contexto da Ciência da Informação, a dimensão ontológica e epistemológica dos conteúdos informacionais. Para fundamentarmos essa perspectiva estrutural do conceito de informação, torna-se necessário que direcionemos nosso olhar para as características semióticas, no caso presente, partindo-se da visão conceitual de Saussure (2012) e Hjlemslev (1975), e representações simbólicas que esse bem de consumo é capaz de apresentar.

\section{A informação e sua perspectiva semiótica}

Sendo os media o meio de veiculação da informação, há nesse ambiente todo um sistema de signos que abrange a fundamentação e compreensão do sujeito para que a notícia ou mensagem possa transmitir uma determinada informação. Por essa razão, devemos visualizar o conceito de informação a partir do conceito semiótico de signo, materializando a interpretação da informação a partir de suas características ontológica e epistemológica.

\section{Uma compreensão do conceito de signo a partir de Ferdinand de Saussure (1857-1913) e Louis Hjelmslev (1899-1965)}

Saussure (2012) desenvolve o conceito de signo a partir da análise do circuito da fala. Considera a fala um ato individual e que pressupõe no mínimo dois sujeitos para que o diálogo se estabeleça por completo. A dinâmica nesse processo se constitui pela associação intrínseca entre o conceito e as imagens psíquicas que são desencadeadas pelos sujeitos em um método de comunicação. Nesse contexto, Saussure (2012) considera que o signo linguístico é uma entidade psíquica de duas faces, se configura a partir da inter-relação entre conceito e imagem acústica (ou psíquica).

Contudo, Saussure (2012) enfatiza que não devemos associar o signo linguístico à união de uma coisa a uma palavra, mas sim o conceito à imagem acústica, sendo que esta não se materializa na representação de um som, mas na impressão psíquica que o som é capaz de nos direcionar ao testemunho de nossos sentidos.

Podemos exemplificar da seguinte maneira: a fórmula molecular da água, $\mathrm{H}_{2} \mathrm{O}$, corresponde a um signo. Ao considerarmos que cada letra maiúscula corresponde a um átomo de um elemento químico e que combinados em uma proporção específica darão origem à molécula de água, estamos atribuindo um significado ao signo, isto é, $\mathrm{H}_{2} \mathrm{O}$ é o símbolo que representa a substância Água. O conteúdo inteligível que se deseja desenvolver no indivíduo é a relação do signo da substância água com o objeto abstrato elaborado na estrutura cognitiva do sujeito, remetendo à construção de um interpretante que represente a molécula de água.

O exemplo apresentado nos mostra a necessidade que a ciência Química tem em recorrer aos signos para representar as especificidades dos materiais e suas transformações. $\mathrm{O}$ signo nesse processo corresponde à mediação entre o sujeito e o mundo à sua volta, mais especificamente, entre o conceito e a imagem psíquica evocada pelo signo. Gois e Giordan (2007, p. 
35) afirmam que "a mediação é a principal característica dos signos, pois eles se colocam entre o sujeito e o mundo tanto para organizar atividades de produção material e simbólica, quanto para estruturar o pensamento".

A definição de signo está diretamente associada com aquilo que representa alguma coisa, algum objeto. É aquilo que de certa forma representa algo a alguém, sugerindo-lhe um signo mais elaborado. Destaca-se, aqui, o circuito da fala de Saussure (2012) na construção do significado de um signo, no qual a imagem acústica se configura como uma associação entre o objeto percebido e os construtos teóricos que o sujeito possui. Dessa forma, a referência que Saussure (2012) faz à imagem acústica não pode ser interpretada como algo concreto, mas como a sinalização de um processo de desenvolvimento conceitual que vincula o signo a representação do objeto.

A esse respeito, Piaget e Inhelder (2011) visualizam a mediação entre signos como uma transição entre o plano de ação, caracterizada pelos objetos que circunscrevem o sujeito, e o plano de proposição hipotética, evidenciada pela articulação do pensamento com as estruturas cognitivas já estabelecidas no sujeito. A complementaridade entre signo e objeto corresponderá a uma expressão que envolve os elementos que formatam o pensamento, a fonologia envolvida no ato da fala, as ações e/ou objetos ausentes e as estruturas cognitivas do sujeito. Esse processo balizará o desenvolvimento formal do pensamento, como propõem Piaget e Inhelder (2011).

Saussure (2012) compreende o signo como sendo a totalidade, a combinação entre conceito e imagem psíquica. De forma didática, o autor afirma que ao usarmos o termo signo nos referimos geralmente à imagem acústica. A fim de reduzir essa ambiguidade, o teórico genebrino faz uma distinção dos termos da seguinte forma: o conceito se refere ao significado e a imagem acústica ao significante. No entanto, é importante considerarmos que os termos não são independentes. Eles coexistem de maneira complementar sustentando a totalidade do signo.

Hjelmslev (1975), em sua obra Prolegômenos a uma teoria da linguagem desenvolve o conceito de signo a partir de um ponto de vista crítico, colocando em evidência a teoria tradicional e moderna da linguística. O teórico dinamarquês tem cuidado ao usar o conceito de signo, considerando que não há uma definição clara de seu significado. Para que possa desenvolver um conceito mais elaborado, o autor se fundamenta na Função Semiótica, a qual se baseia na relação entre duas grandezas: a expressão e conteúdo.

A função semiótica emerge da relação solidária entre expressão e conteúdo. Hjelmslev (1975) elabora uma elucidação do termo signo, retomando a definição tradicional, da qual destaca que signo é tudo aquilo que representa alguma coisa, o objeto. Este objeto, ou essa representação de alguma coisa reside fora do signo, incitando uma grandeza. Considera-se, então, que essa grandeza corresponde à substância do conteúdo. Sendo o objeto direcionado para a substância do conteúdo há, de forma intrínseca, relação com a forma do conteúdo, uma vez que substância e forma não podem coexistir independentemente.

O linguista também afirma que o signo é signo de uma substância de expressão, isto é, enuncia uma sequência de sons que se configura como o resultado do sentido que se estabelece a partir da característica paradigmática da massa amorfa do conjunto de sons da diversidade de línguas. O signo, dessa forma, se liga a uma forma de expressão.

Podemos observar que a caracterização que Hjelmslev (1975) atribui ao signo dialoga com a forma de conteúdo e substância de conteúdo e, também, com a forma de expressão e substância de expressão. O teórico dinamarquês afirma que a forma e a substância das duas grandezas compõem o plano da expressão e o plano do conteúdo. 
Sob esta perspectiva, o teórico formata uma definição do conceito considerando que "deve-se utilizar a palavra signo para designar a unidade constituída pela forma do conteúdo e pela forma da expressão estabelecida pela solidariedade que denominamos função semiótica" (HJELMSLEV, 1975, p. 62).

Ao elaborar uma compreensão do desenvolvimento do pensamento formal, Piaget e Inhelder (2011) sintetizam o significado e os aspectos solidários da função semiótica compreendendo-a como uma forma inteligível de expressar o conteúdo de uma ação, empregando, para isso, significantes diferenciados, ou seja, representações capazes de materializar a ação ou objeto já ausente.

Se extrapolarmos o conceito de signo de Hjelmslev (1975), direcionando-o à compreensão representacional e teórica envolvida nos conceitos químicos, podemos relacionar, abstratamente, os planos de expressão e do conteúdo. Nesse sentido, como afirmam Piaget e Inhelder (2011), a função semiótica corresponde a um processo de representação, pois a reconstrução no plano mental do que estava estruturado no plano das ações se estabelece quando se conjuga, notadamente, signo e significados.

Correlacionaremos a teoria de signo de Hjelmslev (1975) e os aspectos químicos com a caracterização ilustrativa dos estados físicos, interpretados a partir das configurações das partículas e suas movimentações. Nesse exercício abstrativo-representativo, poderemos visualizar, na Figura 1, o plano de expressão e o plano de conteúdo. Isso nos direcionará a uma compreensão do processo de representação proposto por Piaget e Inhelder (2011).

Figura 1. Estados físicos da matéria

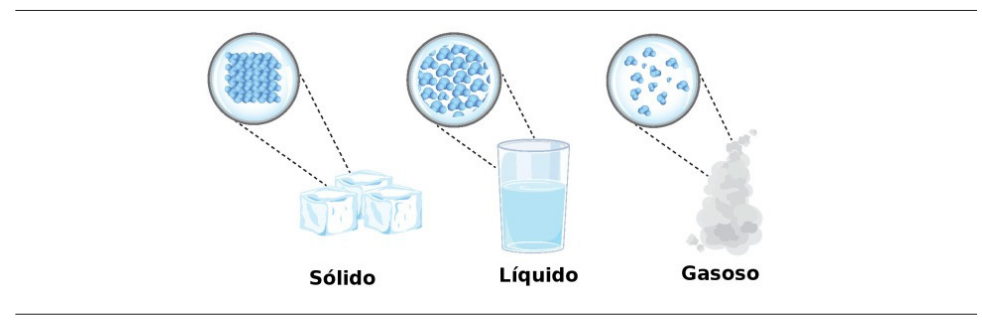

Fonte: adaptada de <https://tinyurl.com/yawa9yhs>. Acesso em: 16 ago. 2018.

A representação das configurações de organização das moléculas corresponde ao que Hjelmslev (1975) chamou de plano da expressão e está diretamente relacionada à formatação dos estados físicos a partir da distância entre as partículas e, de maneira implícita, à movimentação das mesmas. A distância e movimentação das partículas é o que caracteriza e diferencia cada um dos estados físicos. Trata-se do que Piaget e Inhelder (2011) denominaram de materialização da ação ou objeto ausente.

Para que o plano de expressão possa apresentar significado, torna-se necessário vinculá-lo a um conteúdo. O plano de conteúdo é, então, representado pelas palavras embaixo dos desenhos de cada um dos estados físicos. A complementaridade entre o plano de conteúdo e plano de expressão corresponde a uma significação do esquema apresentado, caracterizando cada um dos signos - sólido, líquido e gasoso - aos estados físicos. 
Para que exista um significado, é necessário que o plano de expressão e o plano de conteúdo se apresentem como solidários, designando uma unidade, a qual será caracterizada como signo. Se o plano de conteúdo nos direciona para o conceito e organização do conteúdo e o plano de expressão aos sons e organização dos fonemas, a extrapolação dessas grandezas corresponde direcionar a compreensão dos termos químicos a partir de um plano de abstração e representação. Nesse sentido, Piaget e Inhelder (2011) compreendem esse processo como a reconstrução no plano mental daquilo que estava estruturado no plano das ações e o que irá conferir significado à informação/objeto observado.

Esse contexto teórico que entrelaça o acesso à informação, sua representação e compreensão do conceito de signo fomenta o presente estudo, que tem como objetivo avaliar como a informação acessada e manipulada pelos alunos, por meio das TIC, promove a aprendizagem a partir da articulação e diálogo entre signos distintos em um processo de desenvolvimento da estrutura cognitiva.

\section{Contexto da pesquisa e procedimento metodológico}

Investigar o significado que a informação veiculada pelas TIC apresenta ao processo de ensino e aprendizagem exige uma leitura para além do acesso, manipulação e recortes de conteúdos informacionais. O estudo da utilização das TIC e sua associação com o desenvolvimento da interpretação dos signos que a mensagem visa transmitir, vislumbra, além disso, a interpretação do comportamento do sujeito em momentos distintos.

Sendo assim, para traçarmos uma compreensão do desenvolvimento dos sujeitos envolvidos na pesquisa utilizou-se como método a pesquisa-ação. Thiollent (2009, p. 16) define este método como uma "pesquisa social com base empírica realizada em estreita associação com uma ação ou resolução de um problema coletivo e no qual os pesquisadores e os participantes [...] estão envolvidos de modo cooperativo ou participativo".

Devemos ressaltar que a pesquisa-ação não aprimora apenas a forma como se intervém na prática, mas implica também em uma compreensão da prática por meio de sua melhora (TRIPP, 2005). Assim, a utilização desse método de pesquisa conduziu a uma melhor percepção de como entrelaçar as TIC e a utilização da informação no desenvolvimento da aprendizagem em sala de aula.

Para que o método escolhido pudesse contemplar a especificidade apontada por Thiollent (2009) e Tripp (2005), realizou-se uma pesquisa de doutorado, cujos dados da tese são apresentados como um recorte neste artigo. O estudo deu-se em uma escola pública da rede estadual de ensino da região noroeste de Goiânia, tendo como participantes de pesquisa os alunos de uma turma de primeiro ano do Ensino Médio. A turma escolhida continha 33 (trinta e três) alunos frequentes, dentre os quais a maioria se conhecia.

O professor da turma, autor da pesquisa de doutorado desenvolvida na escola, apresentou a proposta de trabalho aos alunos. A proposta consistia em explorar temas escolhidos e de interesses dos estudantes e, assim, levantar informações sobre os temas escolhidos, a partir das TIC, para discussão. Esse ponto de partida da pesquisa consistiu na primeira estratégia da pesquisa-ação. Thiollent (2009) denomina essa estratégia metodológica de (a) interação explícita entre pesquisadores e as pessoas implicadas na situação investigada. 
Posteriormente à escolha dos temas, os próprios alunos propuseram práticas experimentais que contemplassem a abordagem química das informações pesquisadas. Para este fim, dividiu-se a turma em seis grupos, compostos por 5 a 6 alunos. O objetivo de cada grupo era buscar informações, através das TIC, sobre os temas escolhidos. Após a organização e explicação da dinâmica de trabalho, os temas destacados por cada um dos grupos foram: (1) conservantes e corantes de alimentos; (2) sabão: por que faz espuma?; (3) química do cabelo; (4) química da beleza; (5) lavagem do jeans; e, (6) esmalte.

A delimitação de temas pelos próprios alunos caracterizou outras duas estratégias metodológicas da pesquisa-ação: (b) a prioridade dos problemas a serem pesquisados, e, (c) suas soluções a partir de ações concretas. Estavam imbricadas nessas etapas da pesquisa as intencionalidades da investigação, isto é, compreender como os alunos manipularam as informações acessadas através das TIC e como as direcionaram para o desenvolvimento do conhecimento químico da informação.

Para que se pudesse sistematizar a coleta de dados, após a definição dos temas, o professor-pesquisador estabeleceu um prazo de duas semanas para que os alunos fizessem suas pesquisas e apresentassem o material coletado. Com este fim, solicitou aos alunos que elaborassem uma biblioteca virtual com os links dos sites acessados e os enviassem por e-mail. Desta forma, o professor-pesquisador teria uma perspectiva do tipo de informação que os alunos estavam acessando.

Com os dados das bibliotecas virtuais em mãos, o professor-pesquisador montou um questionário fundamentado nas informações acessadas pelos alunos. Cada um dos grupos recebeu um questionário com aproximadamente 10 (dez) questões, as quais deveriam ser respondidas e entregues ao professor em um prazo de uma semana. O objetivo deste questionário era verificar como as informações sobre o tema pesquisado foram interpretadas, assim como definir a forma de trabalho coletivo para a manipulação da informação.

Após a devolução dos questionários já respondidos pelos alunos, o professor-pesquisador reuniu-se com cada grupo para discutir o que os estudantes haviam compreendido sobre o tema pesquisado e para verificar como a informação era capaz de fundamentar o desenvolvimento da aprendizagem de conceitos químicos. Estas reuniões foram gravadas em vídeo e transcritas. Ao longo das discussões, os desmembramentos dos temas pesquisados resultaram em sugestões de experimentações, que seriam planejadas e executadas de forma conjunta entre o professor-pesquisador e os alunos.

Recorrer às informações pesquisadas para elaborar uma biblioteca virtual, assim como fundamentação para responder ao questionário corresponde a outras estratégias metodológicas da pesquisa-ação. Trata-se de dois pontos fundamentais: (d) acompanhamento das decisões, das ações e de toda a atividade intencional dos atores da situação, e, (e) conhecimento dos pesquisadores e nível de consciência das pessoas e grupos envolvidos nas ações.

Sendo assim, compreende-se que as estratégias metodológicas da pesquisa-ação, associadas à leitura das respostas dos questionários e o trabalho coletivo de discussão e proposição das experimentações, permitiram interpretar a forma como a informação acessada pelas TIC fundamentam os processos de ensino e de aprendizagem. A leitura interpretativa dos dados de pesquisa apresentados nos limites deste trabalho como um recorte de uma pesquisa de doutorado visa apresentar, a partir da análise das respostas dos questionários respondidos pelos alunos, e levando em consideração as discussões das informações dos estudantes com o pro- 
fessor-pesquisador, a relação dos aspectos semióticos presentes na manipulação, interpretação e reelaboração da informação acessadas através das TIC para a formalização do conhecimento químico dos sujeitos envolvidos na pesquisa.

\section{Resultado e discussão}

Os resultados obtidos foram organizados em duas categorias que emergiram das análises feitas dos questionários respondidos pelos alunos. O Quadro 1 apresenta cada uma delas e o que se pretendeu discutir.

Quadro 1. Categorias de análise

\begin{tabular}{|l|l|}
\hline \multicolumn{1}{|c|}{ Categoria } & \multicolumn{1}{c|}{ O que se pretende discutir } \\
\hline $\begin{array}{l}\text { Perguntas } \\
\text { fechadas }\end{array}$ & $\begin{array}{l}\text { Observar a relação que os alunos estabelecem entre a informação pesquisada } \\
\text { e os questionamentos que se assemelhavam aos exercícios em sala de aula, tais } \\
\text { como aqueles nos quais as perguntas eram "O que é?", "Como é feito?", "Qual a } \\
\text { constituição" e etc. }\end{array}$ \\
\hline $\begin{array}{l}\text { Perguntas } \\
\text { subjetivas }\end{array}$ & $\begin{array}{l}\text { Verificar a construção de respostas que exigem uma compreensão e diálogo entre } \\
\text { os signos, presente nas perguntas e informação, e exercício menos mecânico de } \\
\text { manipulação da informação. }\end{array}$ \\
\hline
\end{tabular}

Fonte: elaborado pelos autores.

\section{Perguntas fechadas}

Uma característica comum a todos os grupos, em relação ao acesso e pesquisa das informações na web, foi assinalar, ingenuamente, o conteúdo informacional como redutor do grau de incerteza. Os alunos percebem na informação pesquisada uma ligação intrínseca entre signos distintos, isto é, aqueles presentes na pergunta e os que compõem a informação.

No entanto, a aproximação entre a informação transmitida e acessada pelas TIC e a atividade desenvolvida pelos grupos de alunos não direcionaram os sujeitos a uma mudança de comportamento. $\mathrm{O}$ que houve foi uma perpetuação da passividade frente à informação. A facilidade de acesso a um conteúdo específico e a identidade da informação materializada como um bem público direcionaram a percepção e comportamento dos alunos para a cópia literal de um conteúdo informacional.

Este comportamento é inferido quando o professor-pesquisador, ao discutir as respostas das perguntas fechadas com cada um dos grupos, percebe que os estudantes conseguiam fazer uma referência ao conteúdo informacional, todavia não formalizavam, assimilavam ou mesmo acomodavam a informação como conhecimento. Havia uma tentativa de repetir, durante a discussão, o que era apresentado nas informações elencadas como respostas às perguntas dos questionários.

Nesse processo, o tratamento dado às perguntas fechadas pelos seis grupos mostrou a mesma característica: a informação de interesse é identificada, destacada do conteúdo informa- 
cional e transcrita como resposta. Assim, o grau de incerteza que constitui o desconhecimento de uma resposta à pergunta é reduzido quando o sujeito consegue perceber na informação os signos complementares que justifiquem uma resolução da atividade proposta.

Spyer (2007) destaca que este tipo de manipulação não exige esforço de construção ou elaboração de uma nova informação. A passividade no processo criativo delimita o conteúdo informacional como algo que possa ser simplesmente identificado e copiado.

O exercício mecânico materializado na ação de copiar e colar, ou vulgarmente identificada como dar um ctrl $C+\operatorname{crtl} V$, marginaliza a concepção interpretativa do sujeito e o processo de significação dos signos presentes no conteúdo informacional, desfigurando o propósito de mudança de comportamento do sujeito. Contudo, não podemos desprezar de forma integral esta ação associativa auspiciada pelos alunos. Há nesse processo uma conduta que incita uma predisposição ao desenvolvimento de um comportamento racional que envolve a articulação entre signos.

Piaget e Inhelder (2011) consideram que a cópia se caracteriza como uma conduta comportamental importante, pois prefigura o desenvolvimento do pensamento no sujeito. $\mathrm{O}$ ato de copiar uma informação como resposta a um questionamento deve ser explorado para que se direcione a passividade, frente a um conteúdo informacional, a uma construção cognitiva que entrelace o esforço interpretativo de signos e o desenvolvimento da aprendizagem.

Significa destacarmos no processo de busca por informações relevantes a um tema específico a configuração semiótica de compreensão de um signo (ou vários signos) e a construção abstrata do objeto que o representa. Esta associação entre o signo e abstração do objeto deve compor a interface inteligível construída no processo de assimilação e acomodação (PIAGET, 2007), o que pressupõe uma reciprocidade entre estímulo e resposta.

Suprimir do processo interpretativo a aproximação entre a construção inteligível do significado de um signo e o objeto que o representa implica assumir a informação como um bem público, manipulável distante de uma perspectiva motivacional e coordenada que enfatizam o valor da informação como uma moeda de troca na Economia de Doação, como afirma Kollock (1999).

Este comportamento, ilustrado na cópia literal de um conteúdo informacional é exemplificado pela configuração de resposta elaborada pelo grupo 1, que pesquisou o tema Conservantes e Corantes Alimentares. Observemos a resposta elaborada pelo grupo para o questionamento a seguir:

\footnotetext{
Excerto 1

O que são conservantes e corantes alimentares?

$\mathrm{R}$ - Os corantes servem para adicionar uma coloração melhor ao produto, e garantir que o produto tenha uma cor que chame a atenção do consumidor, e os conservantes garantem que este produto tenha uma vida longa nas prateleiras, durando mais tempo em supermercados, ou na sua casa.
}

Recorrendo ao acervo da biblioteca virtual organizada pelo grupo, encontramos parte do conteúdo informacional contido nos sites pesquisados copiada como resposta. A Figura 2 destaca em vermelho a informação do site, que é a mesma apresentada pelo grupo como resposta ao questionário. 
Figura 2. Informação copiada pelo grupo 1 e apresentada como resposta

$14 / 10 / 2014$

Descrição
Curso de ADITIVOS QUíMICOS E A ALIMENTAÇÃO MODERNA | Buzzero.com

$$
\text { Curtir } 3,8 \mathrm{mil} \text { Tweetar } 0
$$

Os corantes servem para adicionar uma coloração melhor ao produto, e garantir que o produto tenha uma cor que chame a atenção do consumidor, e os conservantes garantem que este produto tenha uma vida longa nas

prateleiras, durando mais tempo em supermercados, ou na sua casa.

\begin{abstract}
O grande problema é que esses aditivos são produtos químicos, e muitas vezes até mesmo tóxicos quando em grande quantidade.O nosso corpo não reconhece essa substância, e não sabe bem o que fazer com ele, ou como eliminá-las do nosso organismo, causando desequilibrios.Podendo até mesmo ser acumulados em nossos órgãos internos, como o figado.
\end{abstract}

Já existe uma grande quantidade de estudos relacionando uma alimentação com grande quantidade de produtos industrializados (contendo corantes e conservantes) com uma série de problemas de saúde. Principalmente em crianças, as quais estão mais em risco, por terem um consumo muito maior.

\title{
Autor(a): Centro Sul Americano De EspecializaÇÃo
}

\section{CONSULTOR DE AUTO-AJUDA ,PSICOLOGIA DA APRENDIZAGEM,CONSULTOR DE PROGRAMAÇÃO NEUROLÍNGUISTICA, CONSULTOR INTELIGÊNCIA EMOCIONAL E PALESTRANTE}

Fonte: Disponível em: <https://tinyurl.com/y7fw9jru>. Acesso em: 16 ago. 2018.

A transcrição integral do fragmento de informação corresponde a uma percepção dos signos do conteúdo informacional que dialoga com o questionário a ser respondido pelo grupo. Destaca a conduta comportamental do sujeito que verifica uma similitude entre os signos de informações distintas. Contudo, essa percepção ainda assume uma definição tradicional do termo, que segundo Lopes e Abib (2002, p. 130), refere-se a um "processo pelo qual entramos em contato com a realidade [...] explicada através da cópia mental do mundo percebido".

Quando o indivíduo copia um fragmento de informação, está elaborando uma representação que está vinculada a uma associação, isto é, apresenta uma percepção da relação entre os signos da informação e do questionário. No entanto, mesmo elaborando essa representação na forma de cópia, o comportamento do sujeito se apresenta passivo diante a informação, pois consegue visualizar os signos que entrelaçam o conteúdo da informação e a pergunta que o incita, contudo não estabelece entre eles um processo de significação. Trata-se de uma assimilação ainda muito incipiente, que necessita ser correlacionada com as estruturas cognitivas já construídas pelo sujeito.

Piaget e Inhelder (2011) consideram o associacionismo um mecanismo de assimilação unilateral de Estímulo $\rightarrow$ Resposta, o qual ainda não se encontra totalmente integrado às estruturas cognitivas já construídas pelo sujeito. Os autores afirmam que o sujeito se tornará sensível aos estímulos exteriores, isto é, à associação, quando assimilados pelas estruturas construídas pelo sujeito, as quais serão modificadas e enriquecidas em função de novas assimilações. 
O comportamento passivo de cópia literal dos alunos, diante da manipulação da informação, é uma conduta que antecede a reorganização das estruturas construídas pelos sujeitos, pois pressupõe a articulação primeira entre signos similares em unidades informacionais distintas. Quando a informação pesquisada é fragmentada e, posteriormente, manipulada, há indícios da identificação de signos - ou significantes, como se referem Piaget e Inhelder (2011) -, no entanto, ainda não diferenciados. Isso impossibilita os estudantes a elaborarem uma representação subjetiva e inteligível do objeto pesquisado.

Assim, se o sujeito em suas percepções do objeto pesquisado consegue estabelecer uma diferenciação e coordenação combinada entre signo e significado, ele está apto a reconstruir em pensamento um objeto ausente por meio de um símbolo ou signo (PILLAR, 1996). No entanto, se a diferenciação e coordenação combinada forem incipientes, a reconstrução do objeto ausente não consegue superar a cópia literal do objeto percebido. Ela apenas coexistirá na presença do próprio modelo.

O esforço do indivíduo em superar a passividade frente à informação corresponde a uma perspectiva incipiente de diferenciação entre signo e significado, consequentemente uma reorganização das estruturas cognitivas já estabelecidas e, assim, um desenvolvimento em função da nova assimilação. Este processo se configura como uma tentativa de coordenação combinada entre signo e representação do objeto ausente, pois a percepção começa a ceder espaço para um processo, ainda superficial, de diferenciação.

Esse distanciamento incipiente da passividade pode ser observado na análise das respostas do questionário do grupo 3, o qual escolheu como tema a química dos cabelos. Algumas componentes do grupo já tinham presenciado esse tipo de tratamento de cabelos, tendo uma delas se submetido a ele, indicando que as estudantes já conheciam o tema antes da atividade ser proposta em sala de aula. A resposta construída pelas alunas para a pergunta: "O que é o processo de alisamento de cabelos?" foi a seguinte:

\section{Excerto 2}

R- O alisamento é um processo químico agressivo, que usa tioglicolato de amônia e que precisa ser feito com muito cuidado.

Apesar da resposta não ser uma elaboração correta, que apresente um esclarecimento ao questionamento, é possível notar que o grupo tentou organizar uma resposta a partir da manipulação e readequação da informação pesquisada e, assim, ajustar o conteúdo pesquisado ao questionário. A Figura 3 mostra o tratamento dado ao conteúdo informacional pelo grupo.

Os destaques em vermelho apresentados na Figura 3 mostram que conjuntos de signos distintos são identificados pelo grupo. A tentativa de coordená-los e estruturá-los em uma resposta à pergunta evidencia que o objeto pesquisado não foi apenas percebido e copiado. Ao relacionarem a característica da substância tioglicolato de amônia ao contexto da resposta elaborada, excluem as substâncias hidroxiladas, pois estão relacionadas ao alisamento e ondulação dos cabelos, enquanto o tioglicolato direciona a interpretação das alunas à substância responsável unicamente pelo alisamento e redução de volume dos cabelos. 
Figura 3. Recorte e manipulação da informação feita pelo grupo 3

O alisamento é um processo químico agressivo, que precisa ser feito com muito cuidado. Separamos então 10 dúvidas sobre a técnica para você evitar danos e ficar lisa como sempre dèsêjoù.

\section{Quais são os ativos que substituem o formol?}

Há quatro substâncias de uso liberado que são capazes de alisar os fios com segurança. Bom para começar o papo com seu cabeleireiro.

- Hidróxido de sódio ou hidróxido de cálcio: Só para os crespos, esses ativos produzem desde um ondulado leve a um liso chapado, dependendo do tempo de contato.

- Hidróxido de Guanidina: Transforma cachos em ondas ou tira o volume dos cabelos lisos. Mas năo deve ser aplicado em fios tingidos porque pode alterar a sua cor.

- Tioglicolato de amônia: Alisa moderadamente e tira o volume de cabelos cacheados. Por ser menos agressivo, pode rolar chapinha ou secador para modelar no fim.

http://mdemulher.abril.com.br/cabelos/reportagem/alisamento/10-duvidas-alisamento-740251.shtml

Fonte: Disponível em: <https://mdemulher.abril.com.br/cabelos/10-duvidas-sobre-alisamento>. Acesso em: 16 ago. 2018.

Consideramos que esta característica da substância tioglicolato apresentada no texto do site fundamenta a estrutura cognitiva dos alunos à assimilação do tioglicolato de amônia como responsável pelo alisamento do cabelo, o que caracteriza que os alunos articulam a combinação dos signos (questionário - site - estrutura cognitiva), os quais atuam em conjunto para formalização de uma nova assimilação. Esta interpretação também indica que o conceito que acompanha a imagem psíquica de um signo se torna significativo quando o signo, já estabelecido cognitivamente pelo indivíduo, fundamenta o desenvolvimento do entendimento de um novo signo percebido. A tentativa de combinação entre signos novos e aqueles já conhecidos sinaliza uma representação, ainda incipiente, da construção do significado do signo para além da cópia literal.

A combinação dos signos percebidos na informação nos remete à proposição teórica de Hjelmslev (1975), que afirma que os signos estão associados a planos de expressão e conteúdo, demonstrando que a língua não é homogênea e que sua heterogeneidade permite rearranjar combinações que direcionam a construções de significados amplos. É o que observamos na resposta elaborada pelo grupo 3. No texto organizado como resposta, a partir dos recortes do conteúdo informacional, a substância tioglicolato de amônia corresponde a um signo, remetendo-o a um significado de substância química específica. Quando o grupo percebe a característica dessa substância (apresentada no próprio site), procuram adicioná-la ao texto que estão formulando como resposta, para dar um significado que contemple o escopo do questionamento. A relação do tioglocolato de amônia com o processo de alisamento também está presente no diálogo do grupo com o professor-pesquisador. 
A construção linguística da resposta apresentada pelo grupo 3 evidencia a percepção de que o signo tioglicolato de amônia possui um significado que complementa a informação pesquisada, estabelecendo relevância para o contexto da resposta a ser elaborada e no próprio diálogo com o professor-pesquisador. A manipulação da informação e seu recorte tornam-se expressivos, pois indicam uma relação entre os conjuntos de signos distintos: aqueles já estruturados cognitivamente e os que são percebidos no corpo da informação pesquisada.

\section{Perguntas subjetivas}

Diferentemente das perguntas fechadas, para as quais os alunos conseguiram apontar uma resposta a determinados questionamentos, a categoria perguntas subjetivas destaca a dificuldade (ou natureza incipiente) de articulação entre a informação pesquisada, o conhecimento prévio e os signos semióticos. Visualizar o objeto pesquisado como algo a ser percebido é um exercício que os alunos conseguem fazer com extrema facilidade. No entanto, interpretar uma informação a partir dos elementos que a constituem corresponde a uma dificuldade acentuada na conduta do indivíduo diante de determinada informação. Essa dificuldade se agrava quando se propõe aos signos agregados à informação uma articulação com o conhecimento prévio do próprio aluno.

Essa é uma dificuldade presente em todos os grupos que participaram da pesquisa, pois coordenar o diálogo entre os elementos semióticos que compõem a informação e são capazes desenvolver um processo de significação em consonância com o conhecimento prévio do indivíduo ainda se apresenta como um obstáculo.

Isto se evidencia quando se pede ao aluno que explique o porquê de determinada afirmação ou simplesmente que elabore uma linha de raciocínio que fundamente a interpretação apresentada. Esta situação se materializou na leitura de algumas respostas elaboradas pelos grupos e nas discussões dos estudantes com o professor-pesquisador a respeito das informações pesquisadas. O exemplo que apresentaremos se refere ao questionário do grupo 1, que continha duas perguntas subjetivas: "Podemos extrair corantes dos alimentos naturais? Se sim, como?" e "Podemos identificar experimentalmente a presença de corantes artificiais nos alimentos? Se sim, como?".

Tais perguntas tinham como objetivo delinear os aspectos teóricos elencados pelas perguntas fechadas e construir uma análise interpretativa e autônoma da própria informação pesquisada. As respostas que os alunos redigiram não apresentaram qualquer indício de conjugação entre os conjuntos de signos percebidos e a interpretação do conteúdo informativo pesquisado. Para a primeira pergunta apresentada o grupo respondeu da seguinte maneira:

\section{Excerto 3}

9 - Podemos extrair corantes dos alimentos naturais? Se sim, como?

R - Sim. Exemplos: o mais comum é o caramelo, produzido pela queima do açúcar ou modificação química do açúcar, outro exemplo é o urucum, corante natural do colorau. $O$ beta-caroteno é outro corante natural, extraído da cenoura, é relacionado com a vitamina A. A chlorella é verde, e derivado das algas. O carmim é um corante derivado da cochonilha (Dactylopius coccus), um inseto parente do pulgão. O suco de beterraba, a cúrcuma, 
o açafrão e as plantas do gênero capsicum são também utilizados como corantes. O dióxido de titânio (E171), um pó que produz coloração branca nos alimentos, é encontrado naturalmente em minerais.

Assim como ocorreu para as perguntas fechadas, as respostas para os questionamentos subjetivos apresentam recortes com informações de vários sites. Isso corrobora a análise anterior, destacando que a percepção dos signos é algo comum para os alunos, mas sua diferenciação ainda é algo incipiente. Nesse sentido, notamos, na redação da resposta apresentada anteriormente, que o signo que se faz presente de forma substancial, tanto na pergunta como na resposta, se expressa no verbo extrair. A resposta elaborada pelo grupo sinaliza positivamente a possibilidade de extração de substâncias corantes de alimentos naturais, isto é, o cerne da pergunta é afirmativamente sinalizado no texto elaborado pelos alunos.

A segunda parte da pergunta é respondida com exemplos de extração e de transformações químicas. $\mathrm{O}$ aspecto relevante desse recorte da informação se concentra na dificuldade do grupo em especificar os processos de separação: a extração e a transformação química de substâncias. A percepção de signos relevantes, no contexto da informação pesquisada, leva os alunos a fazerem referências à queima do açúcar e ao suco de beterraba como processos de obtenção de corantes naturais. Porém, as referências não correspondem a uma representação que os distanciem de uma conduta comportamental com base na cópia. A formulação de uma concepção interpretativa que apresentasse os processos químicos de forma geral e não simplesmente representando exemplos de extração significaria uma elaboração do pensamento fundamentado na interpretação dos signos presentes na informação pesquisada e sua reorganização dialógica com os conhecimentos já estabelecidos cognitivamente.

Esta perspectiva dialógica permitiria que houvesse uma articulação interpretativa em que o raciocínio químico direcionasse a compreensão da queima do açúcar à modificação da matéria, definida como transformação, e a verificação do suco de beterraba como processo de extração de uma substância pela ação de um solvente. São dois apontamentos que explicariam a segunda pergunta do questionamento, e que são apresentados como exemplos de separação de substâncias e transformação da matéria em sala de aula.

Isso evidenciaria a transição entre o plano de conteúdo - caracterizado pela palavra extração -, e o plano de expressão - relação entre o signo e o conteúdo químico que o delimita. Corresponderia ao que Hjelmslev (1975) denominou como função semiótica.

No entanto, o conceito de extração é concebido pelo grupo como singular, pois nos exemplos elencados apresentam sempre a mesma finalidade, se referindo à separação de uma substância de interesse da totalidade de um conjunto de outras substâncias, a partir da ação de um solvente. Esse raciocínio que se encontra embarcado no substantivo extração, contudo no contexto químico não é percebido nem significado pelos alunos.

Ao extrapolarmos a explicação a partir da teoria semiótica de Hjelmslev (1975), podemos dizer que o signo denotado - extração - é compreendido a partir de seu sentido estrito. No entanto, o significado químico é incompreendido pelos alunos. A figura do professor, nesse sentido, torna-se fundamental para a aproximação entre a compreensão do signo em seu plano de expressão e conteúdo.

Esta não correlação entre o signo e o contexto, que lhe atribui um significado capaz de desenvolver uma interpretação que envolva o exercício de abstração e o diálogo entre os signos 
já estabelecidos na estrutura cognitiva do sujeito, dificulta a elaboração do raciocínio a partir de um sistema conceitual. Isso refletirá em obstáculo ao raciocínio assimilativo. Por assimilação, Piaget e Inhelder (2011) pressupõem uma reciprocidade Estímulo $\rightarrow$ Resposta, na qual toda nova ligação se encontra integrada num esquematismo ou em uma estrutura anterior.

A cópia literal se relacionada à assimilação, mas em um nível ainda não articulado com a estrutura já estabelecida cognitivamente pelo indivíduo. Como afirma Piaget e Inhelder (2011), essa assimilação ainda não está integrada a um esquematismo ou estrutura anterior. Os alunos percebem que os corantes podem ser "extraídos" dos alimentos, fato este identificado pelo suco de beterraba na resposta redigida pelo grupo. No entanto, quando são questionados se a partir da prática experimental é possível constatar a presença de substâncias corantes nos alimentos a resposta apresentada é um enfático "não".

\section{Excerto 4}

10 - Podemos identificar experimentalmente a presença de corantes nos alimentos? Se sim, como?

R - Não.

Observamos que a cópia literal está diretamente ligada a uma assimilação, porém ainda não relacionada a uma estrutura cognitiva anterior. Isso nos mostra que a representação, sendo a possibilidade de reconstruir em pensamento um objeto ausente por meio de um símbolo ou signo (PILLAR, 1996), necessita de um facilitador, um interlocutor que possa estabelecer o início de um processo de diferenciação e, a partir daí, coordenar signo e significado para a construção da representação e desenvolvimento da aprendizagem fundamentada na estruturação cognitiva já estabelecida pelo indivíduo.

Entendemos que em sala de aula o professor assume o papel de interlocutor e de facilitador, capaz de estabelecer o elo entre pensamento abstrato e a representação das ações interiorizadas pelo sujeito, promovendo o desenvolvimento de conceitos químicos com significado.

\section{Considerações finais}

Compreender as TIC como uma interface necessária para se estabelecer um circuito de fala atemporal entre sujeitos distintos significa considerar a informação e os artifícios que lhe conferem significado para além da fragmentação dos conteúdos informacionais. Saussure (2012) sustenta a significação dos signos projetando-os em um sentido abstrato, destituindo-o da materialidade do objeto. É o que apresenta Hjelmslev (1975), quando sinaliza a forma e substância que fundamentam a expressão e o conteúdo da função semiótica, caracterizando a complexidade do conceito semiótico de signo. Nesse processo, Piaget e Inhelder (2011) interpretam os aspectos semióticos a partir de uma leitura que entrelaça os planos de ação a uma convergência representativa de objetos ausentes fundamentando a expressividade inteligível de estruturação do pensamento formal.

A informação, neste contexto, deve ser entendida como um conjunto de signos e configurada como um bem de consumo, como destaca Kollock (1999), capaz de fundamentar o pensamento semiótico que envolve a interpretação do conteúdo midiático informacional. 
Consiste em direcioná-la para uma proposição instrumental amparada pela função de transmissão de mensagens e que deve ser manipulada a partir da articulação cognitiva que vise à interpretação e significação dos conteúdos informacionais.

Nos processos de ensino e de aprendizagem, as atividades que envolvem as TIC e o acesso à informação são facilmente assumidas e executadas pelos alunos. No entanto, o uso das TIC e o acesso aos diferentes tipos de informação em sala de aula se configuram como incipientes para o desenvolvimento autônomo da aprendizagem dos estudantes. O conteúdo informacional é facilmente manipulado, fragmentado e colocado em função das atividades pedagógicas pelos alunos. Isso nos mostra que a penetrabilidade das tecnologias e informação é uma realidade que faz parte do cotidiano dos alunos e que permeia a possibilidade de desenvolvimento da aprendizagem.

A compreensão de uma informação dialoga expressivamente com os aspectos semióticos do conteúdo informacional acessado através de qualquer TIC. Sendo assim, a compreensão dos planos de expressão e conteúdo que conferem significado a um signo não podem ser suplantados pelo imediatismo irreflexivo da fragmentação do conteúdo informacional que esteja em consonância com a percepção de signos distintos. Isso nos direciona a uma visualização da mediação do professor em sala de aula de forma efetiva, para que as TIC possam ser utilizadas com significado. $\mathrm{O}$ acesso aos diferentes tipos de informações através das TIC não garantem e, o mais importante, não é sinônimo de aprendizagem.

Podemos inferir que o acesso à informação poderá possibilitar o início de um processo de desenvolvimento, ainda incipiente, de aprendizagem. No entanto, o significado efetivo de uma informação que esteja a serviço do processo de ensino e de aprendizagem se apresentará efetivo a partir da construção dialógica e mediada entre os protagonistas desse processo em sala de aula: professor e aluno, o que resulta na aprendizagem.

A figura do professor como mediador do processo de ensino e de aprendizagem auspicia o desenvolvimento cognitivo em sala de aula, destacando a importância do aspecto dialógico de interpretação, compreensão e desenvolvimento do conhecimento a partir do acesso, manipulação e comunicação da informação acessada através das TIC.

\section{Referências}

CAPURRO, R. Pasado, presente y futuro de la noción de información. Logeion: filosofia da informação, Rio de Janeiro, v. 1, n. 1, p. 110-136, 2014. Disponível em: < http:/ / revista.ibict. br/fiinf/article/view/1494/1672>. Acesso em: 22 ago. 2015.

CAPURRO, R.; HJORLAND, B. O conceito de informação. Perspectivas em Ciência da Informação, Belo Horizonte, v. 12, n. 1, p. 148-207, 2007. Disponível em: <https://doi. org/10.1590/S1413-99362007000100012>. Acesso em: 8 mar. 2015.

CASTELLS, M. A sociedade em rede. 16. ed. Rio de Janeiro: Terra e Paz, 2013.

DAMÁSIO, M. J. Tecnologia e educação: as tecnologias da informação e comunicação e o processo educativo. Lisboa: Nova Vega, 2007.

EPSTEIN, I. Teoria da Informação. São Paulo: Ática, 1988. 
GOIS, J.; GIORDAN, M. Semiótica na química: a teoria dos signos de Pierce para compreender a representação. Cadernos Temáticos de Química Nova na Escola, São Paulo, n. 7, p. 34-42, dez. 2007. Disponível em: < http://qnesc.sbq.org.br/online/ cadernos/07/a06.pdf>. Acesso em: 25 mar. 2015.

HJELMSLEV, L. Prolegômenos a uma teoria da linguagem. São Paulo: Perspectiva, 1975.

KOLLOCK, P. The economies of on line coperation: gifts and public goods in cyberspace. In: SMITH, M. A.; KOLLOCK, P. Comunities in cyberspace. London: Routledge, 1999. p. 220-242.

LOPES, C. E.; ABIB, J. A. D. Teoria da percepção no behaviorismo radical. Psicologia: teoria e pesquisa, Brasília, v. 18, n. 2, p. 129-137, 2002. Disponível em: < https://doi. org/10.1590/S0102-37722002000200003>. Acesso em: 12 out. 2014.

MOLES, A. Teoria da informação e percepção estética. Brasília: Universidade de Brasília, 1978.

PAPERT, S. A máquina das crianças. Porto Alegre: Artes Médicas, 1994.

PIAGET, J. Epistemologia genética. 3. ed. São Paulo: Martins Fontes, 2007.

PIAGET, J.; INHELDER, B. A psicologia da criança. 5. ed. Rio de Janeiro: Difel, 2011.

PILLAR, A. D. Desenho e escrita como sistemas de representação. Porto Alegre: Artes Médicas, 1996.

SAUSSURE, F. Curso de linguística geral. 28. ed. São Paulo: Cultrix, 2012.

SHANNON, C. E. A mathematical theory of comunication, The Bell Systems Technical Journal, Murray Hill, v. 27, n. 3, p. 379-423, 1948.

SPYER, J. Conectado: o que a internet fez com você e o que você pode fazer com ela. Rio de Janeiro: Zahar, 2007.

THIOLLENT, M. Metodologia da pesquisa-ação. 17. ed. São Paulo: Cortez, 2009.

TRIPP, D. Pesquisa-ação: uma introdução metodológica. Educação e Pesquisa, São Paulo, v. 31, n. 3, p. 443-466, 2005. Disponível em: < https://doi.org/10.1590/S151797022005000300009>. Acesso em: 9 ago. 2017.

Artigo recebido em 05/07/2017. Aceito em 04/03/2018.

Contato: Universidade Federal de Goiás, Regional Goiás, Unidade Acadêmica Especial de Ciências Humanas, Praça Brasil Ramos Caiado, n. 35, Centro, Goiânia, GO, 76600-000, Brasil. 